ИЗВЕСТИЯ АКАДЕМИИ НАУК ЭСТОНСКОН ССР. ТОМ ХV СЕРИЯ ФИЗИКО-МАТЕМАТИЧЕСКИХ И ТЕХНИЧЕСКИХ НАУК. 1966, № 1

\title{
B. ВИЙРА
}

\section{РАСПРОСТРАНЕНИЕ КОНОДОНТОВ В НИЖНЕОРДОВИКСКИХ ОТЛОЖЕНИЯХ РАЗРЕЗА СУХКРУМЯГИ (Г. ТАЛЛИН)}

Среди стратиграфически важных групп фауны ордовика большое значение в последнее время приобрели конодонты, которые как микрофоссилии успешно используются для расчленения и корреляции разрезов, особенно буровых.

В Балтоскандии ранне- и среднеордовикские конодонты стали систематически изучаться в середине $50-$ х годов. Так, в 1955 г. М. Линдстрём [1] выделил в нижнем ордовике Средней Швеции по конодонтам четыре зоны, а в 1960 г. дал обзор распространения конодонтов в разрезе о-ва Эланд (поздний тремадок - ранний карадок) [2]. С. Сергеева $[3,6,7]$ провела по конодонтам зональное расчленение нижне- и частично среднеордовикских отложений Ленинградской области.

В настоящей статье рассматривается распространение конодонтов в разрезе Сухкрумяги, где обнажаются породы нижнего и частью среднего ордовика: пакерортский $\left(\mathrm{A}_{2-3}\right)$, латорпский $\left(\mathrm{B}_{\mathrm{I}}\right)[4,5]$, волховский $\left(\mathrm{B}_{\mathrm{II}}\right)$, кундаский $\left(\mathrm{B}_{\mathrm{III}}\right)$, азериский $\left(\mathrm{C}_{\mathrm{I}}\right)$ и нижняя часть ласнамягиского $\left(\mathrm{C}_{\mathrm{Ib}}\right)$ горизонта. Общая мощность изученного на конодонты разреза составляет приблизительно 12 м. Всего было отобрано и обработано 78 образцов. Места взятия образцов указаны в табл. 1. Известняковые образцы подвергались обработке $10-15 \%$-ной уксусной кислотой, а пески и песчаники промывались только водой. В образцах диктионемового сланца пакерортского горизонта конодонты не были обнаружены, вероятно, из-за несовершенной методики их извлечения. Самыми богатыми оказались образцы из латорпского, волховского и кундаского горизонтов, а также из маардуской пачки пакерортского горизонта; менее многочисленны конодонты ласнамягиского горизонта; образцы из азериского горизонта содержали лишь единичные экземпляры.

Самые древние конодонты найдены в песчанике маардуской пачки, верхняя часть которой. мощностью 1 м содержит многочисленные экземпляры. Образцы, взятые с глубины 1,2 и 1,4 м ниже верхней границы пачки, оказались пустыми. Почти все конодонты оболювого песчаника относятся к роду Cordylodus с преобладанием видов C. angulatus, $C$. rotundatus и C. prion. Представители $C$. angulatus морфологически разнообразны: встречаются экземпляры с округленными передним и задним краями зубцов, некоторые даже с плоской передней частью основания; другие более сплюснутые и имеют округленно-острые края, а второстепенные зубцы расположены далеко друг от друга. Непостоянство морфологических признаков наблюдается также у представителей C. rotundatus. Кроме кордилодусов, обнаружены некоторые виды простых конодонтов Acodus, Oneotodus и Oistodus. 
В нижней части латорпского горизонта $\left(\mathrm{B}_{\mathrm{I}} \alpha\right)$, представленной глауконитовым песком ируской пачки, встречаются в большом количестве различные представители простых конодонтов. Исключением являются единичные экземпляры $C$. angulatus и $C$. rotundatus, переходящие из нижележащего горизонта. Почти все конодонты йруской пачки относятся к родам Acodus, Drepanodus, Oistodus, Acontiodus, Paltodus, Scolopodus и Scandodus - все простые конусообразные конодонты. Наиболее характерными являются Acodus deltatus, A. erectus, Acontiodus latus, Scandodus pipa, Oistodus parallelus и др. Единичными экземплярами представлены многие пока еще не определенные виды Acodus, Paltodus, Acontiodus, Scolopodus и Drepanodus. Нижняя и верхняя части ируской пачки имеют несколько отличные комплексы конодонтов, благодаря появлению Scolopodus rex, Oistodus contractus, Drepanodus suberectus в верхней половине пачки и нахождению Oneotodus variabilis только із нижней части ее. Интересно отметить, что в нижней части ируской пачки все конодонты представлены только в виде фрагментов.

Хотя многие из видов, распространенных в ируской пачке, продолжают существовать в глауконитовом известковистом песчанике мяэкюлаской пачки ( $\left.\mathrm{B}_{I} \beta\right)$, комплексы конодонтов этих двух стратиграфических подразделіений отличаются значительно. В мяэкюлаской пачке впервые появляется целый ряд видов, как Oistodus lanceolatus, O. triangularis и др. Характерны для этой пачки многочисленные представители родов Oistodus и Scolopodus - O. lanceolatus, O. forceps, Sc. rex и др. Единичными экземплярами представлены такие характєрные виды, как Prioniodus elegans, Pr. evae, Falodus prodentatus, Drepanodus cyranoicus.

Выше по разрезу все опробованные горизонты представлены различного состава известняками. Почти все конодонты мяэкюлаской пачки продолжают существовать в вышележащей пяйтеской пачке. На границе этих двух пачек появляются некоторые новые конодонты - Prioniodina inflata, Falodus simplex, Scandodus rectus.

Более резкое изменение состава конодонтовой фауны происходит на границе пяйтеской и сакаской (=верхняя часть $\mathrm{B}_{\mathrm{II}} \alpha$ - по схеме Ламанского) пачек, где основные виды предыдущих двух (или даже трех) стратиграфических подразделений перестают существовать и появляется целый ряд новых - Prioniodina flabellum, Trichonodella alae, Acontiodus rectus и др. Большая часть из них переходит в вяэнаский подгоризонт волховского горизонта $\left(\mathrm{B}_{\text {II }} \beta\right)$, где прибавляются некоторые новые, на. пример Oistodus brevibasis, O. originalis, Tetraprioniodus minax и др. Наиболее характерны для волховского горизонта в целом следующие конодонты: Trichonodella alae, Prioniodina flabellum, Cordylodus perlongus и др.

Почти все конодонты, встречающиеся в волховском горизонте, не переходят в вышележащий кундаский горизонт - там встречен совсем иной комплекс конодонтов. Резкая граница в вертикальном распространении конодонтов здесь может быть отчасти обусловлена перерывом в отложениях (отсутствует нижняя половина кундаского горизонта). Наиболее многочисленны здесь представители родов Prioniodus, Ambalodus, Amorphognathus и Paracordylodus. В нашем материале встречаются следующие виды, изображенные, но не описанные $M$. Линдстрёмом [ [2]: Prioniodus sp. 1, Ambalodus sp. 4, Amb. sp. 2, Amorphognathus sp. 1, Paracordylodus sp. 1, Scandodus sp. 1, Scolopodus sp. 2 (=Sc. cornuformis), Prioniodina sp. $1, P r$. sp. 2. Кроме них можно назвать Oistodus forceps, O. complanatus, Falodus parvidentatus и др. 
В азериском горизонте встречаются в основном те же виды. Но в тю время как в образцах из кундаского горизонта многие виды представлены десятками, или даже сотнями экземпляров (Prioniodus sp. 1 Lind., Ambalodus, Paracordylodus, Tetraprioniodus и др.) в образцах из азериского горизонта встречены только единичные конодонты. Впервые появляется в азериском горизонте Panderodus.

Қонодонты ласнамягиского горизонта имеют несколько иной характер, хотя в основном продолжают встречаться представители тех же родов, что в двух предыдущих горизонтах (Prioniodus, Paracordylodus, Ambalodus, Amorphognathus), но в большем количестве, чем в азериском. Наиболее часто в ласнамягиском горизонте встречаются Paracordylodus lindstroemi, Tetraprioniodus asymmetricus, Prioniodus variabilis, Ambalodus sp. 5 Lind., Scolopodus cornuformis и др. Представители последнего вида стали укороченными, по сравнению с экземплярами из кундаского горизонта, и напоминают Scolopodus sp. 3 Lind. Конодонты ласнамягиского горизонта характеризуются сравнительно большими размерами и тем, что относительно большая часть у конодонта занимает полость основания и окружающая ее часть, которая хорошо сохранилась. Такими особенностями обладают, например, Paracordylodus lindstroemi, Tetraprioniodus asymmetricus, Prioniodus variabilis, Oistodus robustus. В нижележащих кундаском и азериском горизонтах (частью и в волховском горизонте) представители этих же родов (Paracordylodus, Tetraprioniodus, Prioniodus) редко встречаются целыми экземплярами.

Перечисленные комплексы конодонтов являются неполными, так как пока не удалось определить все имеющиеся экземпляры.

Из изложенного видно, что в распространении конодонтов в разрезе Сухкрумяги можно заметить несколько довольно резких границ. Хорошо выделяются комплексы, приуроченные к маардуской, ируской, мяэкюлаской и пяйтеской пачкам, а также к волховскому, кундаскому и даже ласнамягискому горизонтам. Менее четок комплекс конодонтов азериского горизонта. Выделяемые здесь комплексы соответствуют конодонтовым фаунам $M$. Линдстрёма $[1,2]$. Комплекс маардуской пачки, характеризующийся многочисленными кордилодусами, сходен с I фауноӥ M. Линдстрёма из тремадокских отложений (табл. 2). II фауна М. Линдстрёма (хуннебергские слои, самые низы аренига) соответствует нашему комплексу ируской пачки $\left(\mathrm{B}_{\mathrm{I}} \alpha\right)$. Конодонты мяэкюлаской и пяйтеской пачек $\left(\mathrm{B}_{\mathrm{I}} \beta, \mathrm{B}_{\mathrm{II}} \alpha^{1}\right)$ очень напоминают III фауну $M$. Линдстрёма из биллингенских слоев. Здесь имеется много общих форм: Oistodus lanceolatus, O. forceps, Prioniodus evae, Scolopodus rex, Distacodus stola и др.

Четвертый компілекс нашего разреза (волховский горизонт) почти тождествен IV фауне конодонтов (лимбатовый известняк). Общими являются здесь Cordylodus perlongus, Trichonodella alae, Prioniodina flabellum, Acontiodus rectus и др. О большом сходстве V фауны М. Линдстрёма с нашим комплексом конодонтов кундаского горизонта говорилось уже выше. Последняя, VI фауна выделена М. Линдстрёмом для верхов разреза о-ва Эланд (лландейло - низы карадока), некоторые конодонты которой определены в нашем материале из ласнамягиского горизонта.

Конодонты в разрезе Сухкрумяги имеют также много общих видов с нижнеордовикскими конодонтами Ленинградской области. Зона Cordylodus angulatus C. Сергеевой [3] идентична с комплексом конодонтов маардуской пачки разреза Сухкрумяги. Следующая зона Drepanodus sculponea подразделена C. Сергеевой на три подзоны, причем нижнюю - подзону Drepanodus proteus - можно в общем сравнивать с 


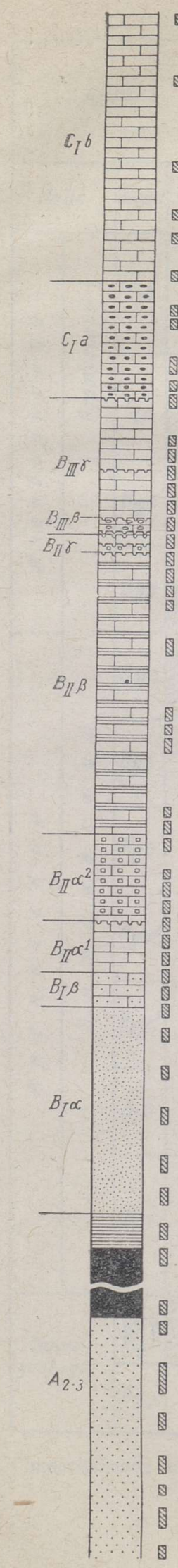

ТАБЛИЦА

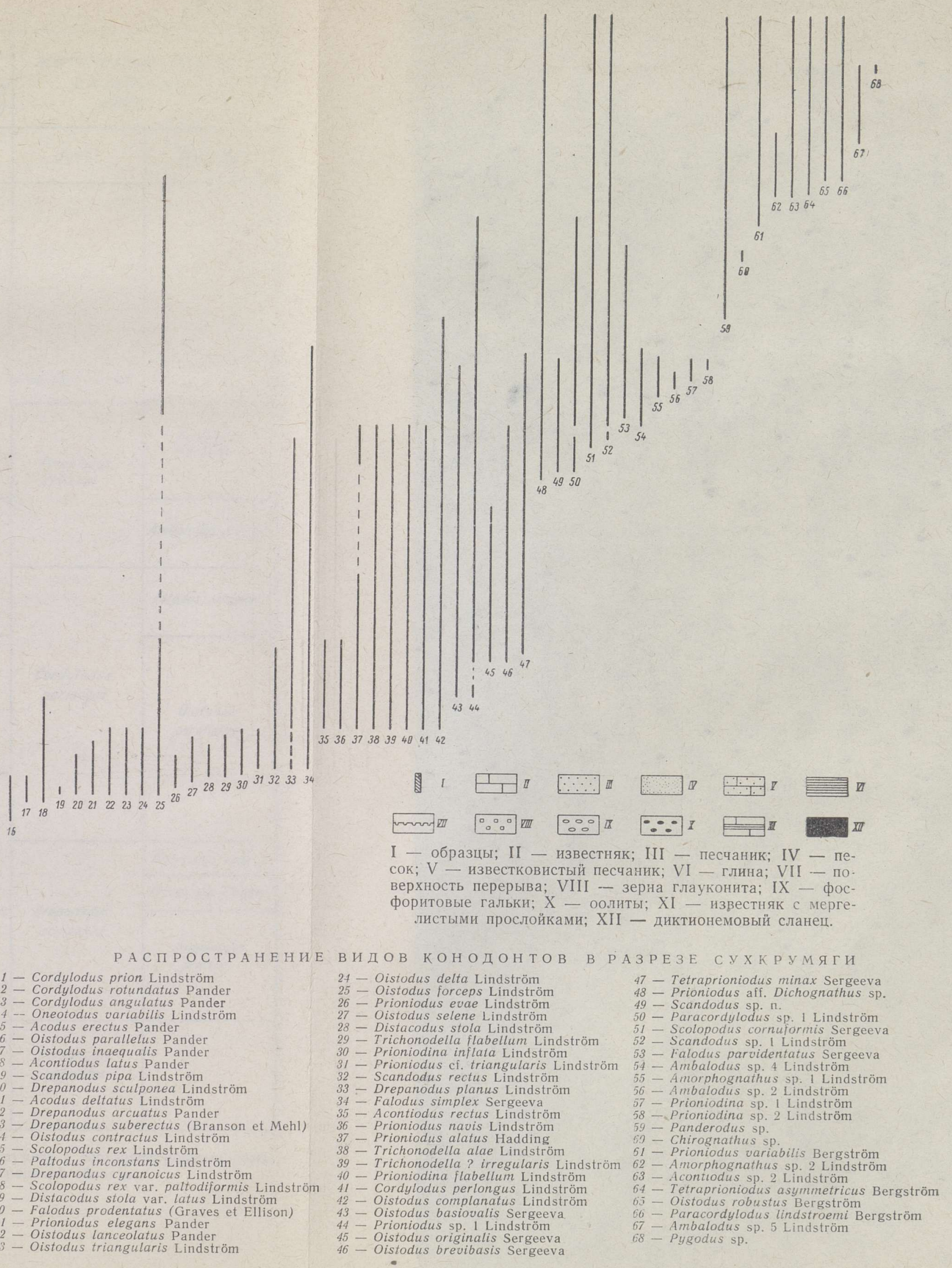


ТАБЛИЦА 2

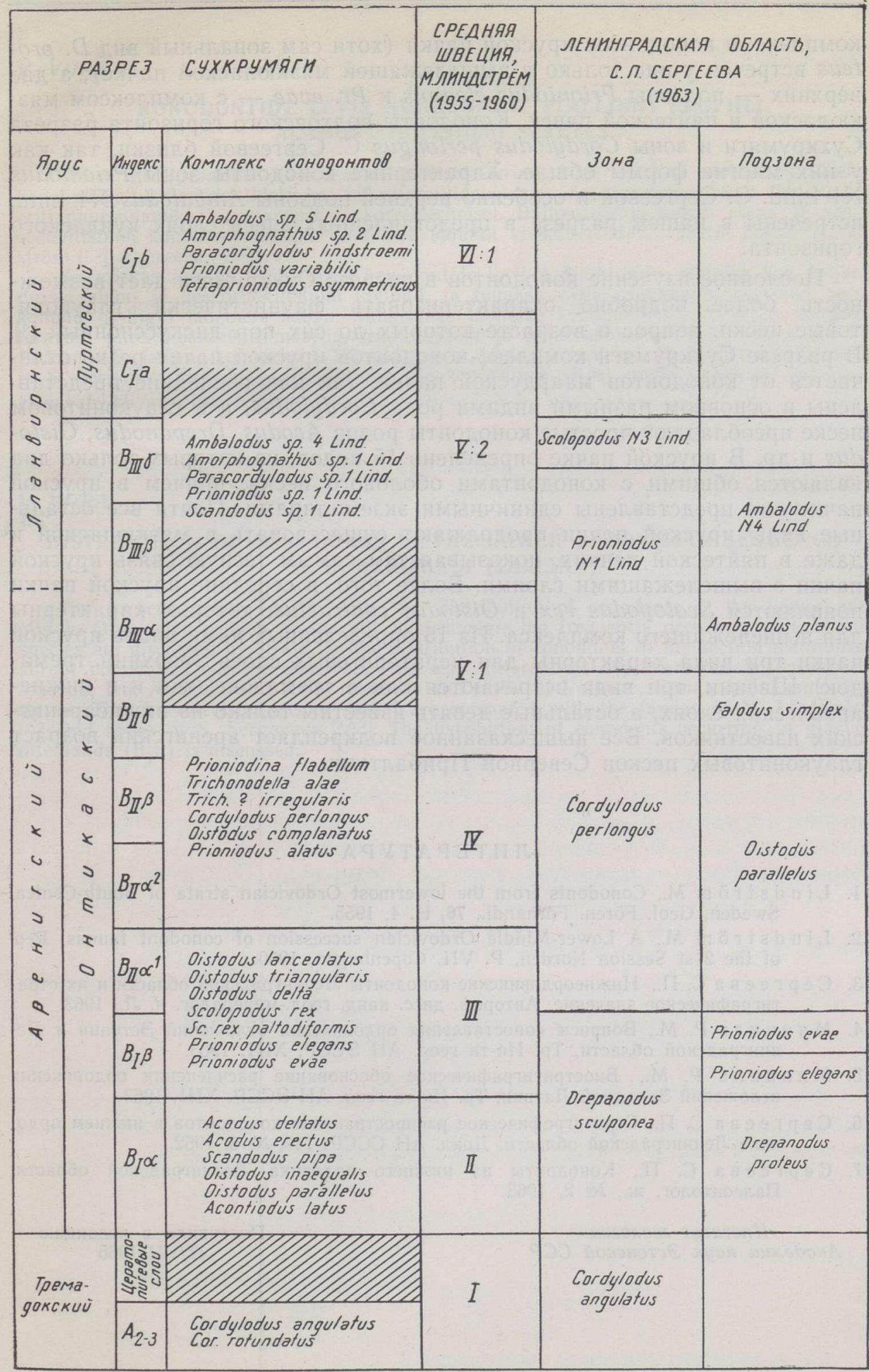

Сопоставление комплексов конодонтов разреза Сухкрумяги с соответствующими комплексами Средней Швеции и Ленинградской области. 
комплексом конодонтов ируской пачки (хотя сам зональный вид D. proteus встречен у нас только в вышележащей мяэкюлаской пачке), а две верхних - подзоны Prioniodus elegans и Pr. evae - с комплексом мяэкюлаской и пяйтеской пачек. Конодонты волховского горизонта разреза Сухкрумяги и зоны Cordylodus perlongus C. Сергеевой близки, так как у них многие формы общие. Характерные конодонты зоны Prioniodus N1 Lind. С. Сергеевой и особенно верхней подзоны Ambalodus N4 Lind. встречены в нашем разрезе в представленных здесь слоях кундаского горизонта.

Послойное изучение конодонтов в разрезе Сухкрумяги дает возможность более подробно охарактеризовать фаунистически глауконитовые пески, вопрос о возрасте которых до сих пор дискуссионный [4]. В разрезе Сухкрумяги комплекс конодонтов ируской пачки резко отличается от конодонтов маардуской пачки, так как последние представлены в основном разными видами рода Cordylodus, а в глауконитовом песке преобладают простые конодонты родов Acodus, Drepanodus, Oistodus и др. В ируской пачке определено 15 видов, из которых только два являются общими с конодонтами оболового песка, причем в ируской пачке они представлены единичными экземплярами. Почти все остальные виды ируской пачки продолжают существовать в мяэкюлаской и даже в пяйтеской пачках, показывая тем самым тесную связь ируской пачки с вышележащими слоями. Более того, в середине ируской пачки появляются Scolopodus rex и Oistndus contractus, которые характерны для вышележащего комплекса. Из 15 определенных нами видов ируской пачки три вида характерны для цератопигевых слоев (верхний тремадок) Швеции, три вида встречаются как в тремадоке, так и в нижнеаренигских слоях, а остальные девять известны только из нижнеаренигских известняков. Все вышесказанное подкрепляет аренигский возраст глауконитовых песков Северной Прибалтики.

\section{Л И Т Е Р А У Р А}

1. Lindström M., Conodonts from the lowermost Ordovician strata of South-Central Sweden, Geol. Fören. Förhandl., 76, H. 4, 1955.

2. Lindström M., A Lower-Middle Ordovician succession of conodont faunas, Rep. of the 21st Session Norden, P. VII, Copenhagen, 1960.

3. С ер ге е в а С. П., Нижнеордовикские конодонты Ленинградской области и их стратиграфическое значение, Автореф. дисс. канд. геол.-минералог. н. Л., 1963.

4. М янни и ь Р. М., Вопросы сопоставления ордовикских отложений Эстонии и Ленинградской области, Тр. Ин-та геол. АН ЭССР, ХІІІ, 1963.

5. Мянниль Р. М., Биостратиграфическое обоснование расчленения ордовикских отложений Западной Латвии, Тр. Ин-та геол. АН ЭССР, XIII, 1963.

6. С ергее в а С. П., Стратиграфическое распространение конодонтов в нижнем ордовике Ленинградской области, Докл. АН СССР, 146, № 6, 1962.

7. Сергеева С. П., Қонодонты из нижнего ордовика Ленинградской области, Палеонтолог. ж., № 2, 1963.

Ннститут геологии

Академии наук Эстонской ССР

Поступила в редакцию 17/VII 1965 
V. VIIRA

\section{KONODONTIDE LEVIK SUHKRUMÄE (TALLINN) PROFIILI ALAMORDOVIITSIUMI SETETES}

Uldise stratigraafilise väärtusega kivististe uurimisel on viimasel ajal suurt tähelepanu pööratud konodontidele kui mikrofossiilidele, mida kasutatakse edukalt läbilõigete, eriti puursüdamike liigestamisel ja korreleerimisel. Baltoskandias hakati alam- ja keskordoviitsiumi konodonte uurima käesoleva sajandi viiekümnendate aastate keskel (Lindström $[1,2]$, Сергеева $[3,6,7])$.

Käesolevas artiklis käsitletakse konodontide levikut Suhkrumäe profiilis, kus paljanduvad alam- ja keskordoviitsiumi kivimid, ja tuuakse välja sagedamini esinevad perekonnad ja liigid lademete kaupa. Suhkrumäe läbilöike konodontide levikus on märgata teravaid piire. Eralduvad maardu, iru, mäeküla ja päite kihistiku ning volhovi, kunda ja lasnamäe lademe kompleksid. Võrreldakse eraldatud komplekse $M$. Lindströmi faunade ja S. Sergejeva tsoonidega. Arutatakse glaukoniitliivas $\left(B_{I} \alpha\right)$, mille vanus on vaieldav, esinevate konodontide levikut.

\section{VIIRA}

\section{DISTRIBUTION OF CONODONTS IN THE LOWER ORDOVICIAN SEQUENCE OF SUHKRUMÄGI (TALLINN)}

The present article deals with the distribution of conodonts in the Lower and Middle Ordovician section of the hill Suhkrumägi; the frequently occurring genera and species are discussed by strata. In the distribution of conodonts in the section mentioned, abrupt boundaries may be observed. One may differentiate the characteristic species of Maardu, Iru, Mäeküla and Päite members and those of Volkhov, Kunda and Lasnamägi stages. The characteristic species stated are compared with the faunas of $M$. Lindström $[1,2]$ and zones of $\mathrm{S}$. Sergeyeva $\left[3^{3,6,7}\right.$. The distribution of conodonts occurring in glauconite sands $\left(B_{I} \alpha\right)$ is discussed. 